\title{
INTERACTIVE EDUCATIONAL SOFTWARE OF TEXTILE DESIGN
}

\author{
Francisco Hernández-Abad ${ }^{1}$, José Ignacio Rojas-Sola², Vicente Hernández-Abad ${ }^{1}$, \\ Manuel Ochoa-Vives ${ }^{1}$, Jordi Font-Andreu ${ }^{1}$, David Hernández-Díaz ${ }^{1}$, Ricardo Villar-Ribera ${ }^{1}$ \\ ${ }^{1}$ Polytechnic University of Catalonia, Department of Engineering Graphics, Barcelona, Spain \\ ${ }^{2}$ University of Jaén, Department of Engineering Graphics, Design and Projects, Jaén, Spain
}

Correspondence to Francisco Hernández-Abad (fhernandez@ege.upc.edu)

\begin{abstract}
This paper presents a novel educational software package which develops an Interactive Didactic Application (IDA) created in the Polytechnic University of Catalonia (UPC), and which contains the essentials of Textile Design. It is an open application which uses a database in ASCII format. The principal elements of this database are lists of whole numbers structured according to indexed colors in standard RGB format. This generates a rational system of indexes of numerical lists, which allows us to transmit knowledge in the different areas which use images in their processes, with application in Textile Design, Engineering Graphics, mathematical transformations or indexation logic, among others.
\end{abstract}

Keywords: Educational Software, Interactive Didactic Application (IDA), Geometric Transformations, Colour, Textile Design.

\section{INTRODUCTION. AIMS \& OBJECTIVES}

The origin and principal reason for the research behind this article is the need to prepare a specific tool to make understanding of the concepts of textiles easier for students of Textile Engineering. Although the application has been conceived as a tool to support teaching in different areas, the latest trends in the development of interactive teaching applications have been followed [1-3], so we consider that this may be considered a powerful tool for training.

The tool therefore takes into account usability [4], interaction [5], accessibility (all the actions have been grouped around a main screen, which gives a clear and understandable user system), visibility of 
the training concepts (the original matrix and the matrix resulting from the latest action are both visible), and the speed of response.

The fact that this application is a powerful tool is backed by the results of the questionnaire and the two questions given to the experimental group. Since the results were not sufficiently clear in some aspects, the questionnaire has been maintained, as the data provided have been analyzed without a great degree of difficulty. Variations have been added to the additional questions, which has increased the efficiency of the analysis of the qualitative data from the academic year 2009-2010, as is shown in the detailed analysis of these data.

The teaching of subjects related to design includes many complex concepts and the assimilation of these concepts can be significantly improved using specifically designed new technologies, which can be used by experienced teachers to improve the teaching-learning process.

This research can be situated in the framework of "teaching innovation" and "improvement in teaching quality”, which forms the basis of the current work of many University Departments, Educational Institutions and Research groups worldwide.

Textile design plays an important role in the development of a society, and a key factor is innovation [6,7], which relates design and technology in the search for aesthetically pleasing designs that fall within technical limits in order to create useful fashions.

Textile designers have to understand that the connections between creativity, science and technology surpass traditional borders, in order to create new and innovative solutions which provide a response to the global multicultural industry [8]. It is therefore vital to research consumer preferences [9].

Many concepts are analyzed and related, such as visual perception, color, contrast, brightness, lighting, along with other more mathematical concepts such as applications, geometric transformations, Boolean operations or matrix calculus. These concepts demonstrate usual processes in the textile industry and also show efficiently the behavior of models created to satisfy specific needs.

This research group, which has been involved for several years in this type of research, has created an open tool for students of textiles, which allows a progressive understanding of many of the important 
concepts related to color, as well as allowing them to progress in mathematical calculus using common operations in textiles. Some of the concepts that the students should assimilate are:

1. To establish a correspondence between the RGB color system and whole numbers.

2. To establish a correspondence between ${ }^{\circ}$ bonds and numerical matrices based on ones and zeros, justifying and deducing the restrictions of the textile bonds.

3. To establish a correspondence between any textile pattern and an associated matrix of whole numbers which reflects its current state, and can adapt to variations in the pattern.

4. To interpret geometric transformations on a plane through variations in pattern, and appreciate their relationship with matrix calculus, and to show results on screen.

5. To associate the actions which affect the numerical matrix with changes in the visualization of a grid representing the pattern on screen.

6. To learn to handle list of data through generic indices of the elements of the representative matrix.

\section{SOFTWARE REVISION}

The applications developed cover a wide field, which includes development of algorithms to aid textile design [10], interactive applications for the design and simulation of textile images [11], applications relating to descriptive geometry [12], multimedia tools for distance learning [13], visualization of visual characteristics using fractal geometry [14], CAD interfaces [15] and 3D Software Graphics [16].

We have also worked specifically in the field of graphic design of patterns and their management. For example, a methodology has been published for the graphic design and redesign of patterns applicable to textile patterns [17], as well as for a set of automatic descriptors for the automatic classification of textile design [18], and for a computational model for the analysis and classification of patterns using symmetry group theory [19]. We have had access to industrial software used in the design of patterns for ceramic materials [20], although this is not a training application, but we have also found information relating to various industrial applications [21] which have been developed to facilitate real-life textile operations, some of which are being used by students of this specialty. 
However, none of the applications analyzed have been developed using software applications which are open to students in the field of textiles. Some of the teachers belonging to our research group created a software package in C++ called DISTEX [22].

We found however that these programs do not make it possible to appreciate the changes in the databases which they use, as they work with packet files, and neither is it possible to establish the relationships or correspondences which allow the user to deduce the concept on which the processes are based. They are end programs, which the user learns to use in order to achieve the predicted results, and therefore they have a reduced capacity to increase the basic learning of the students.

\section{SOFTWARE USED}

The programming software chosen for the development of the application is Adobe Authorware 7 [23], a tool which allows the intuitive development of sophisticated programs. The basis of the programming system is primarily graphic, although it includes all the analytical tools of high level programming languages in a format similar to $\mathrm{C}++$, which makes it ideal for programming any type of application. The working environment is also very user friendly, with programming based on icons, objects and option menus.

It has the possibility to be packaged in WEB format, which allows the creation of multimedia applications for e-learning in which graphics, sound, animation, text and video can be controlled from within the working environment. In addition, it allows the use of tool libraries and off-line exits to run other applications, giving results which can be used without leaving the application. Its graphical format makes it ideal for programs in which a good treatment of color and screen resolution are indispensable.

\section{METHODOLOGY}

The methodology used is that which is usual in a teaching innovation project. The director of the research team, after various meetings which the team, drew up a text which outlined the objectives, along with other related ideas. This text, in which some of the ideas included images which were already in use, as well as other new draft images, was given to all members of the team so that they 
could carry out a preliminary analysis, to gain a clearer idea of the viability of the project and its possibilities for implementation. After a joint consideration in which solutions were provided to some of the problems raised, the project is considered to be viable and the team is coordinated: team leader, content writers, designers of geometric models, designers of textile patterns, members of postproduction team, analysts and layout.

The start of the project required various prior steps:

- $\quad$ Define the area of interest.

- $\quad$ Define the objectives.

- $\quad$ Define the content.

- Define the necessary infrastructure and the means with which to obtain it.

- Generate necessary resources.

- $\quad$ Acquire equipment and programming licenses.

- $\quad$ Prepare the equipment and software.

- Train the team members in the use of programs dealing with CAD textile, illustration, image treatment, simulation and programming, among others.

A conceptual map of the application was developed, with various outlines, guides, interactions, hyperlinks and programming algorithms.

Following this preparatory work and training, work began on programming the interface in order to bring it into line with the objectives. As a consequence of this work, it was necessary to produce common algorithms to allow access to the principal routines, divided logically into nine sections, each with access to the corresponding actions. Care was taken to integrate the menu system in the environment, so that it took up the little working environment. A color palette is always accessible along with related actions, and the legibility of all the texts included in the menus, dialogue boxes and contextual help is assured.

Following the latest trends, which avoid large scale demonstrations in favor of intuitive graphic sequences, the team attempted to design a teaching model covering the most important concepts 
relating to color, such as the correspondence between binary numbers and the RGB components of the color palette or between these components and whole numbers.

We observed quickly that the material generated was much more efficient than conventional material, as all the color characteristics, including depth of color, changing from one system to another or conversion between palettes of different depth were assimilated extremely quickly. The effects of the changes could be seen immediately and with only a little reasoning, a person with no specific knowledge of the field could understand them easily.

Figure 1 shows the interface, and the spaces dedicated to each task are clearly distinguishable. The menu bar, the color palette and the working area are permanent elements. The figure shows two temporary elements in the working area: the "Transformations" drop-down menu, and a colored grid representation of the pattern which is being worked on at that moment.

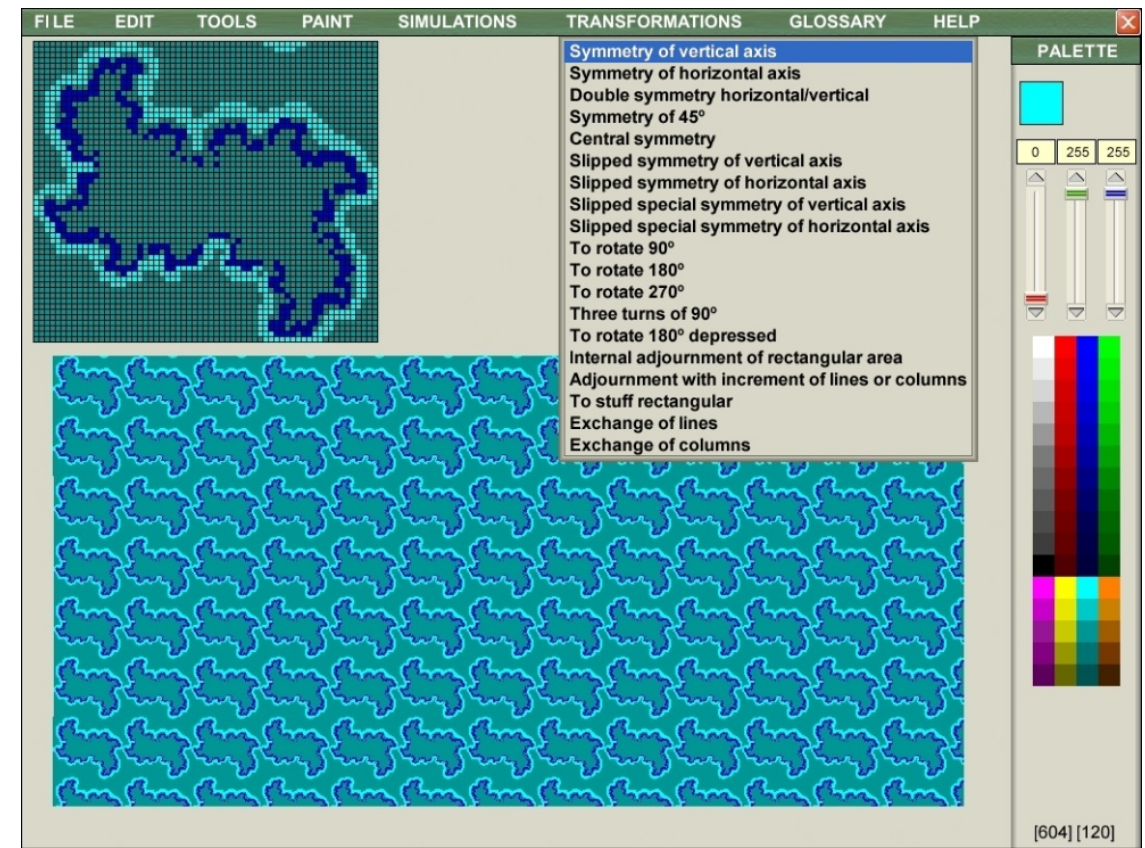

Figure 1. Application Interface.

Figure 2 shows a simplification of the general structure of the application, which has a central nucleus with the system of principal menus, hidden behind the group named "nummenu_\&_submenu”, and is formed by the following menus: Edit, Palette, Paint, Simulations, Transformations, Glossary and Help. 


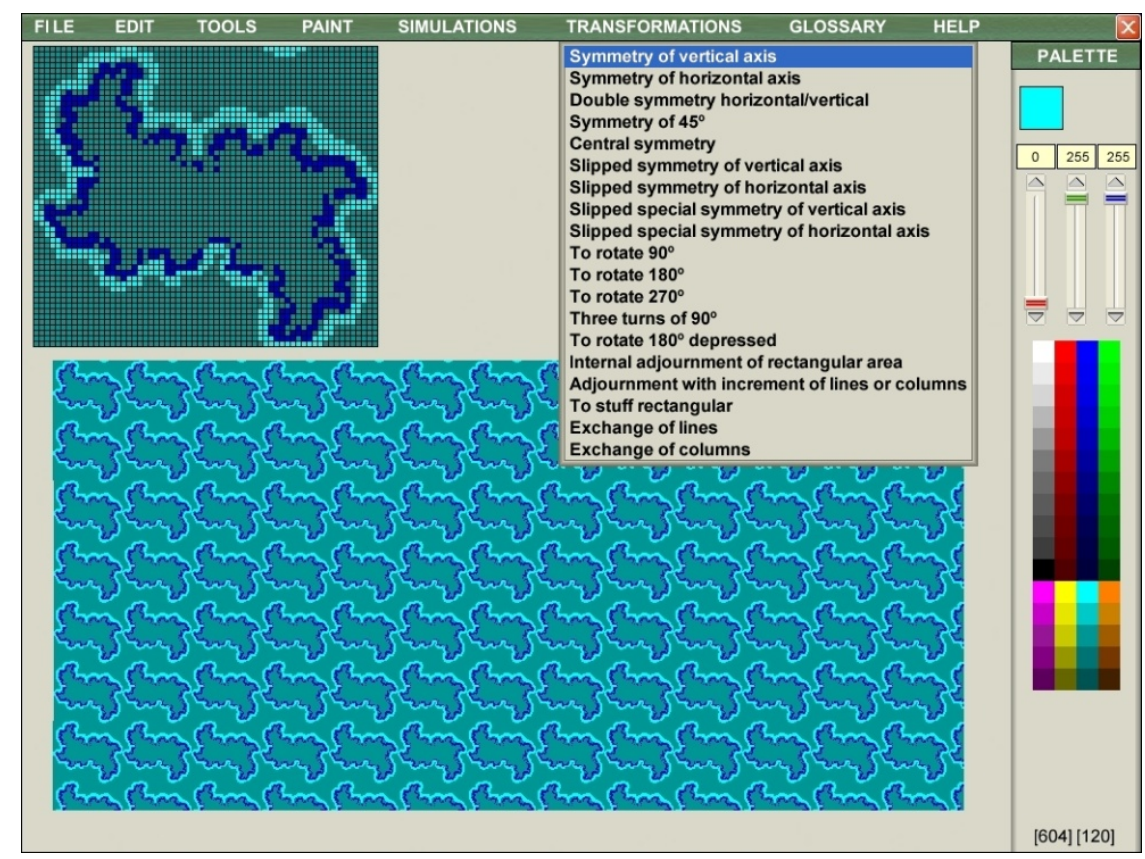

Figure 1. Application Interface.

Figure 2 shows a simplification of the general structure of the application, which has a central nucleus with the system of principal menus, hidden behind the group named "nummenu_\&_submenu", and is formed by the following menus: Edit, Palette, Paint, Simulations, Transformations, Glossary and Help. 


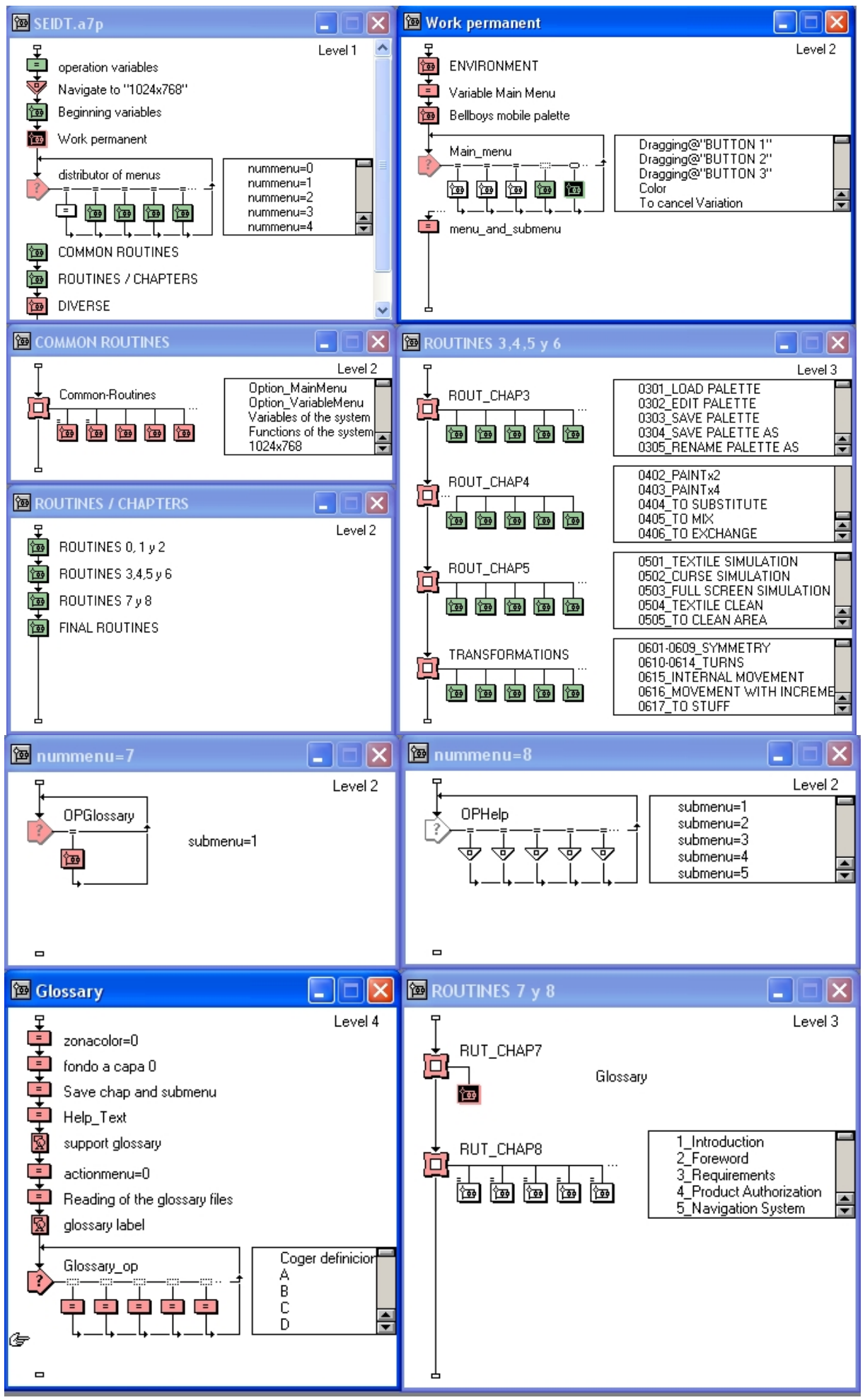

Figures 2a \& 2b. Simplified General Outline.

After choosing the menu and option, the user is taken to the chosen action sequence by the group named "menu distributor" which redirects the user towards specialized routines. These routines are independent, and have sporadic access to common routines, which carry out specific roles such as 
stopping a sequence to allow reflection on the action developed, or requiring information to continue and action, etc. Figure 2 also shows the simplified structure of the Index, Glossary and Help, which are explained below.

In order to show all the research work which is behind each concept to be transmitted, the information relating to programming is complemented by the source code of one of the calculus groups belonging to the specialized routine "Transformations - Symmetry of vertical axis", which is one of the routines of the group "Routines 3, 4, 5 \& 6" (figure 3).

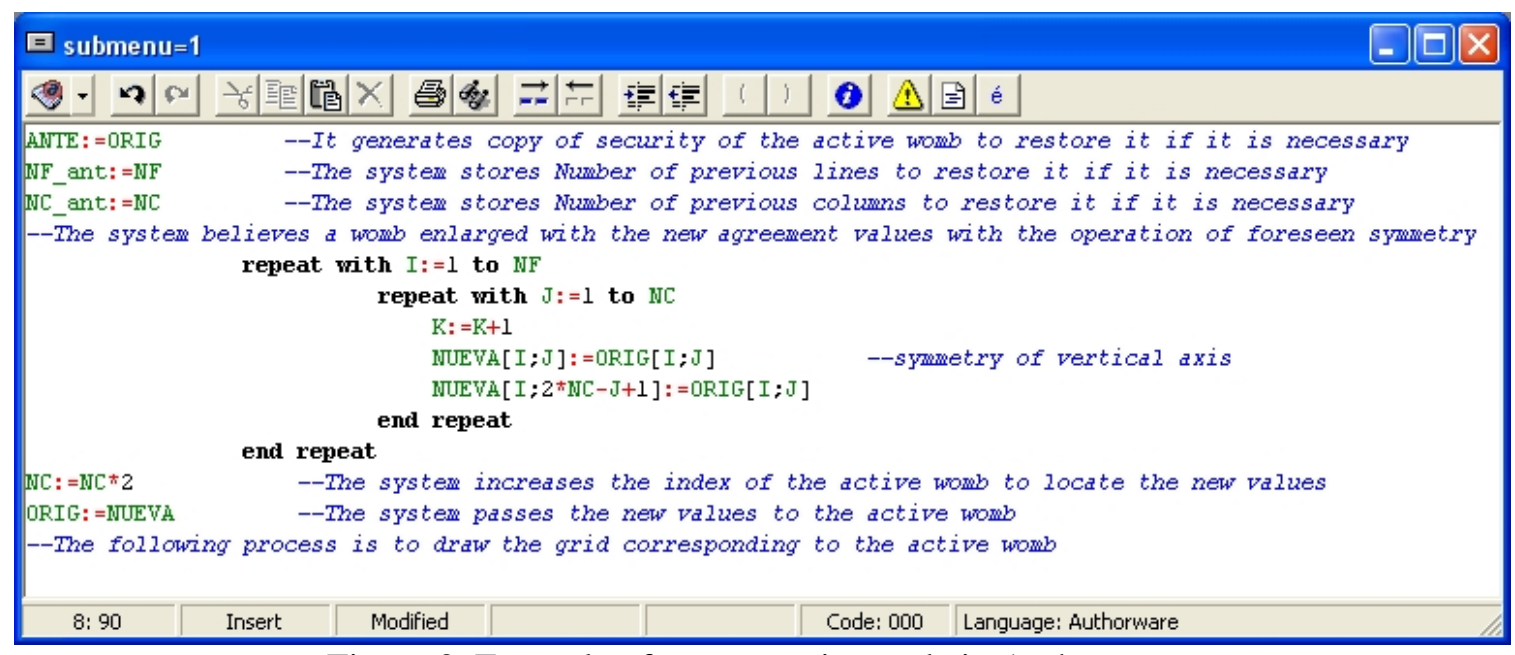

Figure 3. Example of programming code in Authorware.

\section{DEVELOPED APPLICATION}

The application has been developed for operating systems compatible with Microsoft Windows, and it runs correctly in Windows XP, Windows 2000 and Windows Vista. It has the typical sections of any software for industrial use, but as its characteristics must make it useful for teaching purposes, aspects which promote this didactic character have been given increased importance. This article shows several examples of this.

The navigation system is top-down, although some aspects have been given characteristics of artificial intelligence. The action is directed through the principal menus towards specific routines, which work with knowledge objects to return control to the principal nucleus once they have been run. During the process the repetitive code sequences are often downloaded using links to common routines.

Some of these sequences use calls to specialized libraries to optimize performance, although we have attempted to use as far as possible our own tools, to avoid incompatibilities arising from changes in the 
characteristics of standard operating systems (it is better for the style and size of texts to depend on the developed software, so that they are independent of the system).

The interface has permanent access to the principal menus, even though in some sections there are up to 5 levels of depth.

\section{Working}

When the application is run, the main window appears (figure 1). This man window shows the 8 principal menus: File, Edit, Tools, Paint, Simulations, Transformations, Glossary and Help.

A pre-designed and saved palette is opened with the name Standard.pal, and a default pattern is prepared. This means that all the options are operative, which would not be the case without either the palette or the pattern.

As a demonstration of this educational software, and owing to its size, we have chosen three sequences, with the following objectives:

- To assimilate the relationship between binary numbers and RGB color palettes.

- To assimilate the concept of textile bonds.

- To assimilate working with numerical matrices through the indexation of their elements.

Below is a description of the work carried out in the first section:

In order to approach the first section, it is convenient first to know how the software works internally relating to the assignation of colors to points on the screen in the chosen color system. Concepts such as screen resolution and depth of color should be explained. Even though these are concepts which make up part of various areas of textiles, definitions have been included in the glossary of terms, so that students can confirm their degree of knowledge by contrasting these definitions with material they have learnt.

The objective of this stage is for students to be able to:

- Know the difference between the capacity of color of the monitor, the graphics card and the software used.

- Know what a graphic palette is and distinguish between the range of possible colors and those which can be shown simultaneously on screen. 
- Understand the difference between color palettes of 8, 16, 32 and 64 bits.

- Know how to define in binary form RGB colors in different palettes, as well as how to convert them where possible.

- Learn the concept of correspondence between binary numbers and whole numbers, and convert them both ways.

- Assimilate the change of colors from an 8-bit palette to one of 16, 32 o 64 bits such that the resulting color is equivalent, and understand that this is not possible in the other direction.

The first thing that has to be assimilated is that using a certain number of binary digits, it is possible to differentiate a maximum of numbers:

With one digit, 2 numbers can be represented $\left(2^{1}\right)$ :

0,1

With two digits, 4 numbers can be represented $\left(2^{2}\right)$ :

$00,01,10,11$

With three digits, 8 numbers can be represented $\left(2^{3}\right)$ : $000,001,010,011,100,101,110,111$

With four digits, 16 numbers can be represented $\left(2^{4}\right)$ : 0000, 0001, 0010, 0011, 0100, 0101, 0110, 0111 1000, 1001, 1010, 1011, 1100, 1101, 1110, 1111

This reasoning shows that each binary digit multiplies by 2 the number of possible combinations, so that if there are 8 digits, the possible combinations are $2^{8}=256$

After seeing how the program is capable of distinguishing in RGB 256 tones of each component (from 0 to 255), it is easy to deduce that the number of possible colors is $256 \times 256$ x $256=16,777,216$

The following step is to clarify that a depth of color of 24 bits means that 8 bits are used for each of the components, that is, 256 combinations for Red, 256 for Green and 256 for Blue.

Given that the majority of high level languages require whole numbers to differentiate between components, it is necessary to explain how the conversion is made from binary, and vice versa.

Let ABCDEFGH be a binary number in which each letter corresponds to a 0 or a 1 , then (still in binary form): ABCDEFGH = A0000000+B000000+C00000+D0000+E000+F00+G0+H

Where, as in the decimal system, the whole equivalent is:

$\mathrm{H}^{*} 2^{0}+\mathrm{G} * 2^{1}+\mathrm{F}^{*} 2^{2}+\mathrm{E}^{*} 2^{3}+\mathrm{D} * 2^{4}+\mathrm{C} * 2^{5}+\mathrm{B} * 2^{6}+\mathrm{A}^{*} 2^{7}$ 
The reverse process is more complex, as to pass from a decimal number to binary it is necessary to perform divisions by the base (2) to the highest power, obtain the whole quotient (which will be the corresponding digit) and the module, which then must be divided again by the base to the power immediately below to obtain the following digit ( 0 or 1$)$. This process must be repeated until the binary number is completed.

For values applicable to a 24-bit palette, and using only one component, the logical sequence is:

Let $\mathrm{Z}$ be the decimal value of a whole number in the range described:

- $\quad$ The first figure will be the whole number resulting from division by $2^{7}$ ( 0 or 1 ).

- El remainder of the division is divided by $2^{6}$, giving the second binary digit, until the sequence of 8 digits is completed.

All these objectives are covered (figure 4) by applying this knowledge to the colors of the palette, where the routines implemented allow us to check the skill of the conversions and the effect they have on the color of the palette. Clicking on one of the colors of the palette and varying the components shows immediately the effect produced on this color, on the pattern and on the simulation of the textile which is carried out from the simulation menu.

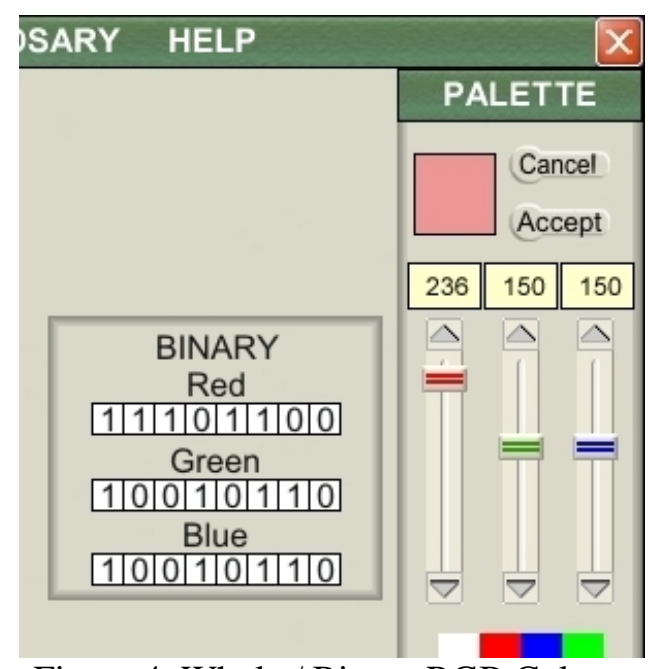

Figure 4. Whole / Binary RGB Colors.

In the palette menu it is also possible to test the conversion of a palette based on a depth of color of 18 bits, which allows patterns created with the previous version of the software to be reused, and view with the same color tones. The students can also see that the process is not possible in the other direction without varying the colors, as the quality of the matrices is much lower. 
The second example refers to the introduction of the concept of textile bond. This concept is directly associated to interwoven textiles, which are made of parallel fibers in two perpendicular directions, and where the fibers cross defines which of the two directions is uppermost [24]. The analytical representation of a rectangular area of interwoven fabric (figure 5) is made with a matrix of binary numbers. The zeros show crosses where the horizontal fiber is hidden, and the ones show the crosses which the horizontal fiber is uppermost.

$\begin{array}{llllllllllllllllllllllllllllllllllllllll}1 & 0 & 0 & 1 & 1 & 1 & 0 & 0 & 0 & 1 & 1 & 0 & 0 & 1 & 1 & 1 & 0 & 0 & 0 & 1 & 1 & 0 & 0 & 1 & 1 & 1 & 0 & 0 & 0 & 1 & 1 & 0 & 0 & 1 & 1 & 1 & 0 & 0 & 0 & 1\end{array}$ $\begin{array}{lllllllllllllllllllllllllllllllllllllllll}0 & 0 & 1 & 1 & 1 & 1 & 1 & 0 & 1 & 1 & 0 & 0 & 1 & 1 & 1 & 1 & 1 & 0 & 1 & 1 & 0 & 0 & 1 & 1 & 1 & 1 & 1 & 0 & 1 & 1 & 0 & 0 & 1 & 1 & 1 & 1 & 1 & 0 & 1 & 1\end{array}$ $\begin{array}{lllllllllllllllllllllllllllllllllllllllll}0 & 0 & 1 & 0 & 0 & 1 & 1 & 1 & 1 & 1 & 0 & 0 & 1 & 0 & 0 & 1 & 1 & 1 & 1 & 1 & 0 & 0 & 1 & 0 & 0 & 1 & 1 & 1 & 1 & 1 & 0 & 0 & 1 & 0 & 0 & 1 & 1 & 1 & 1 & 1\end{array}$ $\begin{array}{lllllllllllllllllllllllllllllllllllllllll}0 & 1 & 1 & 0 & 0 & 0 & 1 & 1 & 0 & 0 & 0 & 1 & 1 & 0 & 0 & 0 & 1 & 1 & 0 & 0 & 0 & 1 & 1 & 0 & 0 & 0 & 1 & 1 & 0 & 0 & 0 & 1 & 1 & 0 & 0 & 0 & 1 & 1 & 0 & 0\end{array}$ $\begin{array}{lllllllllllllllllllllllllllllllllllllllll}0 & 1 & 0 & 0 & 0 & 1 & 1 & 0 & 1 & 0 & 0 & 1 & 0 & 0 & 0 & 1 & 1 & 0 & 1 & 0 & 0 & 1 & 0 & 0 & 0 & 1 & 1 & 0 & 1 & 0 & 0 & 1 & 0 & 0 & 0 & 1 & 1 & 0 & 1 & 0\end{array}$ $\begin{array}{llllllllllllllllllllllllllllllllllllllll}1 & 1 & 0 & 0 & 1 & 1 & 0 & 0 & 0 & 1 & 1 & 1 & 0 & 0 & 1 & 1 & 0 & 0 & 0 & 1 & 1 & 1 & 0 & 0 & 1 & 1 & 0 & 0 & 0 & 1 & 1 & 1 & 0 & 0 & 1 & 1 & 0 & 0 & 0 & 1\end{array}$ $\begin{array}{lllllllllllllllllllllllllllllllllllllllll}1 & 0 & 0 & 1 & 1 & 0 & 0 & 0 & 0 & 1 & 1 & 0 & 0 & 1 & 1 & 0 & 0 & 0 & 0 & 1 & 1 & 0 & 0 & 1 & 1 & 0 & 0 & 0 & 0 & 1 & 1 & 0 & 0 & 1 & 1 & 0 & 0 & 0 & 0 & 1\end{array}$ $\begin{array}{lllllllllllllllllllllllllllllllllllllllllll}1 & 1 & 1 & 1 & 1 & 0 & 0 & 0 & 1 & 1 & 1 & 1 & 1 & 1 & 1 & 0 & 0 & 0 & 1 & 1 & 1 & 1 & 1 & 1 & 1 & 0 & 0 & 0 & 1 & 1 & 1 & 1 & 1 & 1 & 1 & 0 & 0 & 0 & 1 & 1\end{array}$ $\begin{array}{llllllllllllllllllllllllllllllllllllllll}0 & 1 & 1 & 0 & 1 & 1 & 0 & 1 & 1 & 0 & 0 & 1 & 1 & 0 & 1 & 1 & 0 & 1 & 1 & 0 & 0 & 1 & 1 & 0 & 1 & 1 & 0 & 1 & 1 & 0 & 0 & 1 & 1 & 0 & 1 & 1 & 0 & 1 & 1 & 0\end{array}$ $\begin{array}{llllllllllllllllllllllllllllllllllllllll}1 & 1 & 0 & 0 & 0 & 1 & 1 & 1 & 0 & 0 & 1 & 1 & 0 & 0 & 0 & 1 & 1 & 1 & 0 & 0 & 1 & 1 & 0 & 0 & 0 & 1 & 1 & 1 & 0 & 0 & 1 & 1 & 0 & 0 & 0 & 1 & 1 & 1 & 0 & 0\end{array}$ $\begin{array}{lllllllllllllllllllllllllllllllllllllllll}1 & 0 & 0 & 1 & 1 & 1 & 0 & 0 & 0 & 1 & 1 & 0 & 0 & 1 & 1 & 1 & 0 & 0 & 0 & 1 & 1 & 0 & 0 & 1 & 1 & 1 & 0 & 0 & 0 & 1 & 1 & 0 & 0 & 1 & 1 & 1 & 0 & 0 & 0 & 1\end{array}$ $\begin{array}{llllllllllllllllllllllllllllllllllllllll}0 & 0 & 1 & 1 & 1 & 1 & 1 & 0 & 1 & 1 & 0 & 0 & 1 & 1 & 1 & 1 & 1 & 0 & 1 & 1 & 0 & 0 & 1 & 1 & 1 & 1 & 1 & 0 & 1 & 1 & 0 & 0 & 1 & 1 & 1 & 1 & 1 & 0 & 1 & 1\end{array}$ $\begin{array}{lllllllllllllllllllllllllllllllllllllllll}0 & 0 & 1 & 0 & 0 & 1 & 1 & 1 & 1 & 1 & 0 & 0 & 1 & 0 & 0 & 1 & 1 & 1 & 1 & 1 & 0 & 0 & 1 & 0 & 0 & 1 & 1 & 1 & 1 & 1 & 0 & 0 & 1 & 0 & 0 & 1 & 1 & 1 & 1 & 1\end{array}$ $\begin{array}{llllllllllllllllllllllllllllllllllllllll}0 & 1 & 1 & 0 & 0 & 0 & 1 & 1 & 0 & 0 & 0 & 1 & 1 & 0 & 0 & 0 & 1 & 1 & 0 & 0 & 0 & 1 & 1 & 0 & 0 & 0 & 1 & 1 & 0 & 0 & 0 & 1 & 1 & 0 & 0 & 0 & 1 & 1 & 0 & 0\end{array}$ $\begin{array}{lllllllllllllllllllllllllllllllllllllllll}0 & 1 & 0 & 0 & 0 & 1 & 1 & 0 & 1 & 0 & 0 & 1 & 0 & 0 & 0 & 1 & 1 & 0 & 1 & 0 & 0 & 1 & 0 & 0 & 0 & 1 & 1 & 0 & 1 & 0 & 0 & 1 & 0 & 0 & 0 & 1 & 1 & 0 & 1 & 0\end{array}$ $\begin{array}{llllllllllllllllllllllllllllllllllllllll}1 & 1 & 0 & 0 & 1 & 1 & 0 & 0 & 0 & 1 & 1 & 1 & 0 & 0 & 1 & 1 & 0 & 0 & 0 & 1 & 1 & 1 & 0 & 0 & 1 & 1 & 0 & 0 & 0 & 1 & 1 & 1 & 0 & 0 & 1 & 1 & 0 & 0 & 0 & 1\end{array}$ $\begin{array}{lllllllllllllllllllllllllllllllllllllllll}1 & 0 & 0 & 1 & 1 & 0 & 0 & 0 & 0 & 1 & 1 & 0 & 0 & 1 & 1 & 0 & 0 & 0 & 0 & 1 & 1 & 0 & 0 & 1 & 1 & 0 & 0 & 0 & 0 & 1 & 1 & 0 & 0 & 1 & 1 & 0 & 0 & 0 & 0 & 1\end{array}$ $\begin{array}{llllllllllllllllllllllllllllllllllllllll}1 & 1 & 1 & 1 & 1 & 0 & 0 & 0 & 1 & 1 & 1 & 1 & 1 & 1 & 1 & 0 & 0 & 0 & 1 & 1 & 1 & 1 & 1 & 1 & 1 & 0 & 0 & 0 & 1 & 1 & 1 & 1 & 1 & 1 & 1 & 0 & 0 & 0 & 1 & 1\end{array}$ $\begin{array}{llllllllllllllllllllllllllllllllllllllll}0 & 1 & 1 & 0 & 1 & 1 & 0 & 1 & 1 & 0 & 0 & 1 & 1 & 0 & 1 & 1 & 0 & 1 & 1 & 0 & 0 & 1 & 1 & 0 & 1 & 1 & 0 & 1 & 1 & 0 & 0 & 1 & 1 & 0 & 1 & 1 & 0 & 1 & 1 & 0\end{array}$ $\begin{array}{llllllllllllllllllllllllllllllllllllllll}1 & 1 & 0 & 0 & 0 & 1 & 1 & 1 & 0 & 0 & 1 & 1 & 0 & 0 & 0 & 1 & 1 & 1 & 0 & 0 & 1 & 1 & 0 & 0 & 0 & 1 & 1 & 1 & 0 & 0 & 1 & 1 & 0 & 0 & 0 & 1 & 1 & 1 & 0 & 0\end{array}$ $\begin{array}{llllllllllllllllllllllllllllllllllllllll}1 & 0 & 0 & 1 & 1 & 1 & 0 & 0 & 0 & 1 & 1 & 0 & 0 & 1 & 1 & 1 & 0 & 0 & 0 & 1 & 1 & 0 & 0 & 1 & 1 & 1 & 0 & 0 & 0 & 1 & 1 & 0 & 0 & 1 & 1 & 1 & 0 & 0 & 0 & 1\end{array}$ $\begin{array}{llllllllllllllllllllllllllllllllllllllll}0 & 0 & 1 & 1 & 1 & 1 & 1 & 0 & 1 & 1 & 0 & 0 & 1 & 1 & 1 & 1 & 1 & 0 & 1 & 1 & 0 & 0 & 1 & 1 & 1 & 1 & 1 & 0 & 1 & 1 & 0 & 0 & 1 & 1 & 1 & 1 & 1 & 0 & 1 & 1\end{array}$ $\begin{array}{lllllllllllllllllllllllllllllllllllllllll}0 & 0 & 1 & 0 & 0 & 1 & 1 & 1 & 1 & 1 & 0 & 0 & 1 & 0 & 0 & 1 & 1 & 1 & 1 & 1 & 0 & 0 & 1 & 0 & 0 & 1 & 1 & 1 & 1 & 1 & 0 & 0 & 1 & 0 & 0 & 1 & 1 & 1 & 1 & 1\end{array}$ $\begin{array}{lllllllllllllllllllllllllllllllllllllllll}0 & 1 & 1 & 0 & 0 & 0 & 1 & 1 & 0 & 0 & 0 & 1 & 1 & 0 & 0 & 0 & 1 & 1 & 0 & 0 & 0 & 1 & 1 & 0 & 0 & 0 & 1 & 1 & 0 & 0 & 0 & 1 & 1 & 0 & 0 & 0 & 1 & 1 & 0 & 0\end{array}$ $\begin{array}{lllllllllllllllllllllllllllllllllllllllll}0 & 1 & 0 & 0 & 0 & 1 & 1 & 0 & 1 & 0 & 0 & 1 & 0 & 0 & 0 & 1 & 1 & 0 & 1 & 0 & 0 & 1 & 0 & 0 & 0 & 1 & 1 & 0 & 1 & 0 & 0 & 1 & 0 & 0 & 0 & 1 & 1 & 0 & 1 & 0\end{array}$ $\begin{array}{lllllllllllllllllllllllllllllllllllllllll}1 & 1 & 0 & 0 & 1 & 1 & 0 & 0 & 0 & 1 & 1 & 1 & 0 & 0 & 1 & 1 & 0 & 0 & 0 & 1 & 1 & 1 & 0 & 0 & 1 & 1 & 0 & 0 & 0 & 1 & 1 & 1 & 0 & 0 & 1 & 1 & 0 & 0 & 0 & 1\end{array}$ $\begin{array}{llllllllllllllllllllllllllllllllllllllll}1 & 0 & 0 & 1 & 1 & 0 & 0 & 0 & 0 & 1 & 1 & 0 & 0 & 1 & 1 & 0 & 0 & 0 & 0 & 1 & 1 & 0 & 0 & 1 & 1 & 0 & 0 & 0 & 0 & 1 & 1 & 0 & 0 & 1 & 1 & 0 & 0 & 0 & 0 & 1\end{array}$ $\begin{array}{llllllllllllllllllllllllllllllllllllllll}1 & 1 & 1 & 1 & 1 & 0 & 0 & 0 & 1 & 1 & 1 & 1 & 1 & 1 & 1 & 0 & 0 & 0 & 1 & 1 & 1 & 1 & 1 & 1 & 1 & 0 & 0 & 0 & 1 & 1 & 1 & 1 & 1 & 1 & 1 & 0 & 0 & 0 & 1 & 1\end{array}$ $\begin{array}{lllllllllllllllllllllllllllllllllllllllll}0 & 1 & 1 & 0 & 1 & 1 & 0 & 1 & 1 & 0 & 0 & 1 & 1 & 0 & 1 & 1 & 0 & 1 & 1 & 0 & 0 & 1 & 1 & 0 & 1 & 1 & 0 & 1 & 1 & 0 & 0 & 1 & 1 & 0 & 1 & 1 & 0 & 1 & 1 & 0\end{array}$ $\begin{array}{llllllllllllllllllllllllllllllllllllllll}1 & 1 & 0 & 0 & 0 & 1 & 1 & 1 & 0 & 0 & 1 & 1 & 0 & 0 & 0 & 1 & 1 & 1 & 0 & 0 & 1 & 1 & 0 & 0 & 0 & 1 & 1 & 1 & 0 & 0 & 1 & 1 & 0 & 0 & 0 & 1 & 1 & 1 & 0 & 0\end{array}$ Figure 5. Analytical Representation of an area of interwoven fabric.

The graphic representation would be a screen of black squares which correspond to ones, and white squares corresponding to zeros (figure 6). 


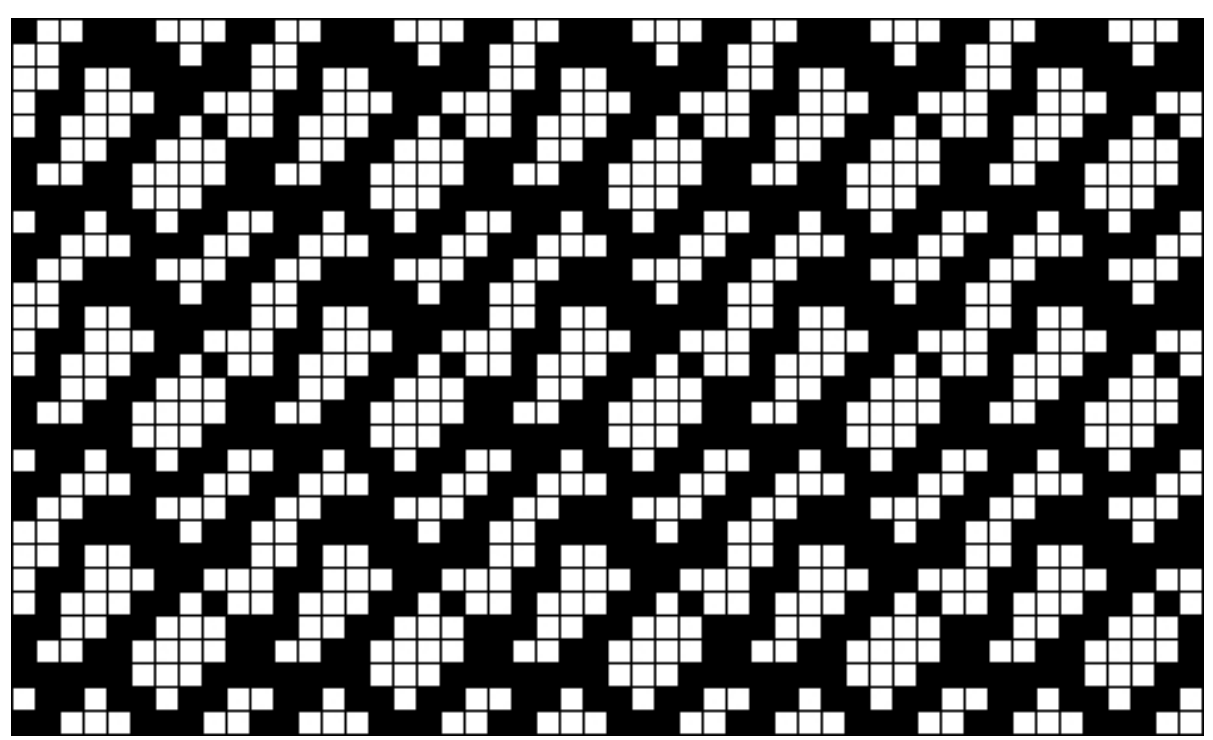

Figure 6. Graphic Representation of an area of interwoven fabric.

The name bond is given to the smallest rectangular block of a fabric which repeats regularly in width and height to form a larger piece of fabric (figure 7 shows the bond corresponding to the previous piece of fabric in numerical format).

$$
\begin{array}{llllllllll}
1 & 0 & 0 & 1 & 1 & 1 & 0 & 0 & 0 & 1 \\
0 & 0 & 1 & 1 & 1 & 1 & 1 & 0 & 1 & 1 \\
0 & 0 & 1 & 0 & 0 & 1 & 1 & 1 & 1 & 1 \\
0 & 1 & 1 & 0 & 0 & 0 & 1 & 1 & 0 & 0 \\
0 & 1 & 0 & 0 & 0 & 1 & 1 & 0 & 1 & 0 \\
1 & 1 & 0 & 0 & 1 & 1 & 0 & 0 & 0 & 1 \\
1 & 0 & 0 & 1 & 1 & 0 & 0 & 0 & 0 & 1 \\
1 & 1 & 1 & 1 & 1 & 0 & 0 & 0 & 1 & 1 \\
0 & 1 & 1 & 0 & 1 & 1 & 0 & 1 & 1 & 0 \\
1 & 1 & 0 & 0 & 0 & 1 & 1 & 1 & 0 & 0
\end{array}
$$

Figure 7. Analytical Representation of the base bond.

Figure 8 shows the graphic representation of the bond and the appearance the fabric would have if the horizontal fibers were white and the vertical fibers black. 


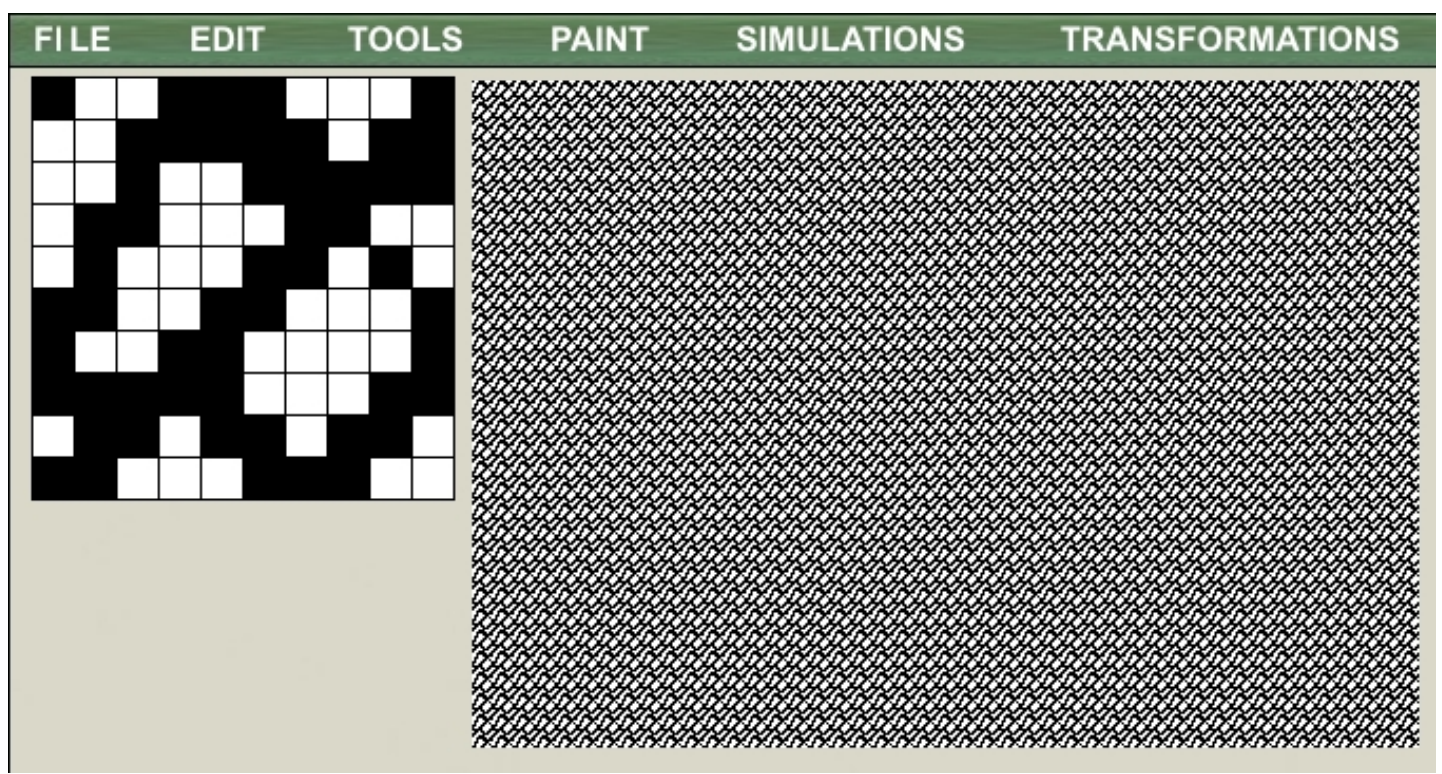

Figure 8. Graphic Representation of a valid textile bond and its simulation.

The software created allows the design of bonds and the deduction of the restrictions or limitations which exist when considering a textile (textiles have a limited number of threads due to the bounds imposed by reality [25], as well as to experience which recommends certain limits [26]).

In the application it is also possible to work with patterns which would not be valid as bonds, but which would be valid as printed patterns. These can use wider ranges of colors, and are especially useful for common operations in professional design programs. As this is an open program, it is useful for checking the effects of operations carried out on these patterns, as well as for allowing free imagination to incorporate tools which other programs do not consider.

To understand this process, it is useful to consider the pattern as a large matrix of points whose elements are the colors of a palette (in our case a palette made up of 64 colors of 24 bits). Each color is represented by a whole number, which to differentiate from other colors, corresponds to the binary number of 24 bits (every 8 binary digits redirects to a whole number between 0 and 255, corresponding to the values of Red, Green and Blue). Likewise, the palette is another matrix, in this case of 64 whole numbers. When one number is substituted for another, this changes the color of all the elements of the matrix which are assigned the same number on the palette. 
From this we can deduce that comprehension of the effects requires also comprehension of working with the indices of the matrices, as the operations performed will move elements of the matrix in some cases, and in others the values will be completely changed or changed in a specific zone.

This is a very useful exercise for students, who can predict what is going to happen to the pattern and check a large number of possible operations through the set of indices. Students can also see how some common operations affect the number of elements of the matrix, which allows them to assimilate the concept of dynamic matrix.

The following is the process to carry out one of the common operations performed on a pre-created pattern, which will give an idea of the process used to deal with this set of indices.

Let $\mathrm{PAL}_{(\mathrm{K})}$ for $\mathrm{K}$ between 1 y 64, be the matrix which contains the colors of the current palette. Consider the matrix $\mathrm{A}_{(\mathrm{MN})}$ from figure 9 as the initial pattern, where the elements $\mathrm{A}_{\mathrm{JI}}$ for $J$ between 1 and $M$ and $I$ between 1 and $N$ are elements of $\mathrm{PAL}_{(\mathrm{K})}$

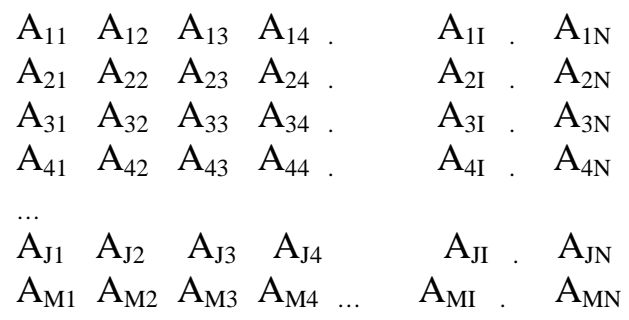

Figure 9. Original Matrix of the pattern.

It must be borne in mind that the operations which are perform on matrix $\mathrm{A}_{(\mathrm{MN})}$ are very diverse, as on occasions they will produce a variation in the range (for example, extension of the horizontal range along a vertical axis of symmetry affecting all the matrix, where the horizontal range would change from $\mathrm{N}$ to $2 * \mathrm{~N}$ ). This forces us to consider matrices with variable range or to initiate the matrix with a new range each time there is a variation of this type. We have chosen the first option, and therefore the control of the indices must be very strict.

In addition, when applications take on a larger scale, the possibility of undoing changes must be taken into account, which forces us to work with a minimum of two more dynamic matrices:

- A matrix $B_{[M N]}$ where the values of $A_{[M N]}$ are saved, and therefore the current matrix can be maintained until the expected changes are produced. 
- A matrix $\mathrm{C}_{[\mathrm{OP}]}$, whose vertical and horizontal ranges are calculated previously according to the operation chosen. This matrix will house the transition values, that is, the new values that are obtained according to the operation chosen.

Once the working philosophy has been assimilated, it is necessary to consider the detail of the strategy followed in some of the operations accessible through the Transformations menu.

In textile jargon $[27,28]$, the names given to plane transformations differ from what is generally understood outside this field; a rotation of $180^{\circ}$ in the original pattern (figure 10) is equivalent to a central symmetry with the axis situated on the bottom right corner of the pattern, where the squares which complete the extended screen are filled with background color.

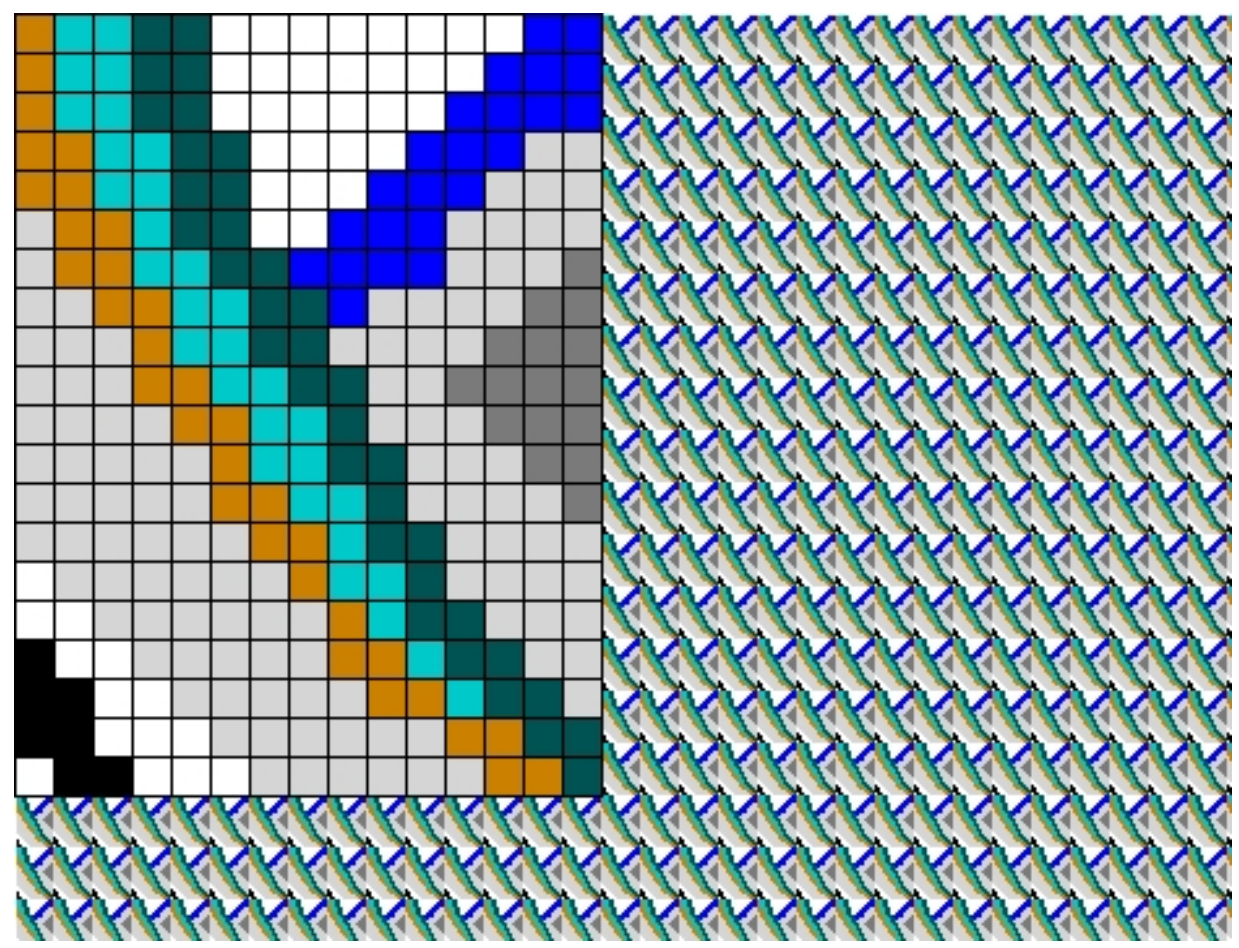

Figure 10. Original pattern to be transformed and fabric simulation.

It is also possible to consider a rotation of $180^{\circ}$, with the center situated on the bottom right corner; the screen is completed by squares filled with background color (figure 11). 


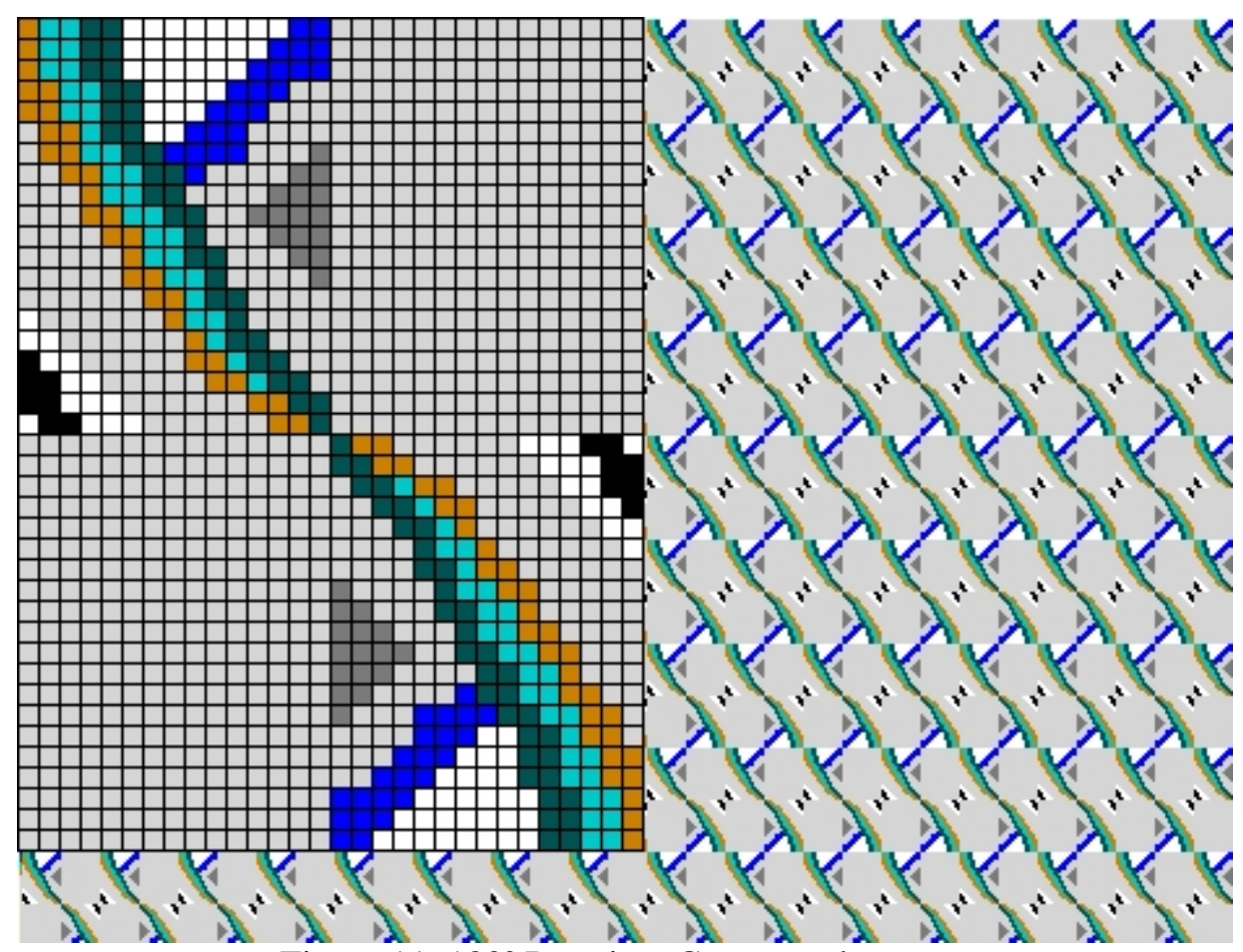

Figure $11.180^{\circ}$ Rotation. Current color grey.

Let us consider the logical sequence which gives rise to this type of transformation and the effect produced both on the transformed matrix and on the simulated fabric which is obtained in both cases.

In order to simplify the process, specific routines have been created to copy the values of a dynamic matrix in another, and colloquial language is used to situate this operation in the sequence, as follows:

1. Transfer the values of $\mathrm{A}_{[\mathrm{MN}]}$ to $\mathrm{B}_{[\mathrm{MN}]}$ as well as $\mathrm{M}$ and $\mathrm{N}$ in the variables $\mathrm{M}_{\text {ant }}$ and $\mathrm{N}_{\text {ant }}$ in order to be able to restore the original values using the undo command in the Edit menu.

2. Create a matrix $C_{[O P]}$ such that $\mathrm{O}=(2 * \mathrm{M})$ and $\mathrm{P}=(2 * \mathrm{~N})$, whose elements $\mathrm{C}_{\mathrm{ij}}$ contain the numerical value which corresponds to the current palette color (default color indexed through $\mathrm{PAL}_{\mathrm{K}}$ where $\mathrm{K}$ is a variable from 1 to 64$)$.

3. $\mathrm{C}_{[i \mathrm{j}]}=\mathrm{A}_{[\mathrm{ij]}]}$ for $(0<\mathrm{i}<\mathrm{M}+1) \mathrm{y}(0<\mathrm{j}<\mathrm{N}+1)$

4. $\mathrm{C}_{[(2 * \mathrm{M}-\mathrm{i}+1),(2 * \mathrm{~N}-\mathrm{j}+1)]}=\mathrm{A}_{[\mathrm{ij}]}$ for $(0<\mathrm{i}<\mathrm{M}+1) \mathrm{y}(0<\mathrm{j}<\mathrm{N}+1)$

5. $\mathrm{M}=2 * \mathrm{M}$

6. $\mathrm{N}=2 * \mathrm{~N}$

7. Initialize $\mathrm{A}_{[\mathrm{M}, \mathrm{N}]}$

8. Transfer the values of $\mathrm{C}_{[\mathrm{M}, \mathrm{N}]}$ to $\mathrm{A}_{[\mathrm{M}, \mathrm{N}]}$

9. Delete $\mathrm{C}_{[\mathrm{M}, \mathrm{N}]}$ 


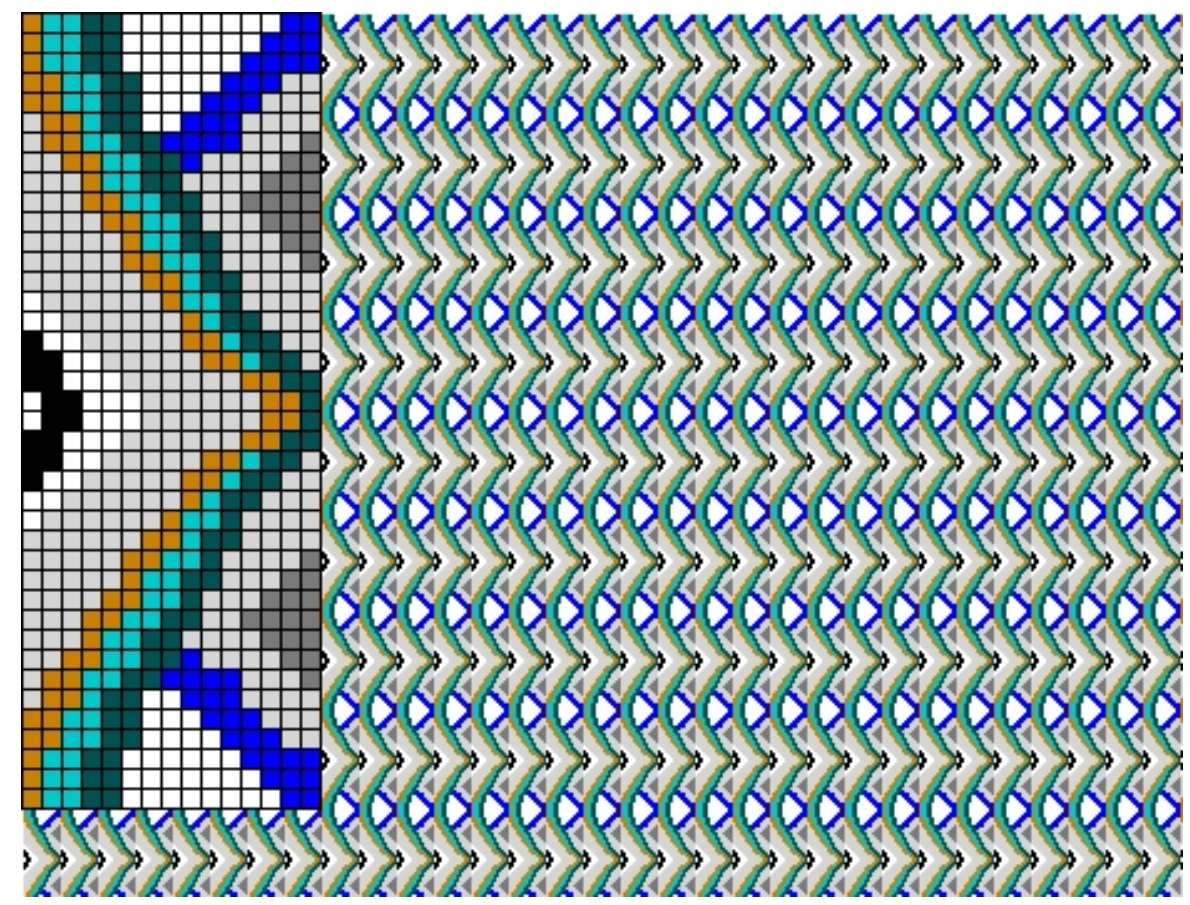

Figure 12. Horizontal axis symmetry.

Other transformations can be considered with similar sequences:

Figure 12 shows the transformed matrix corresponding to a horizontal axis symmetry and its simulation, where points 1, 5, 7, 8 and 9 are identical, whereas points 2, 3, 4 and 6 would be:

2. Create a matrix $\mathrm{C}_{[\mathrm{OP}]}$ such that $\mathrm{O}=(2 * \mathrm{M})$ and $\mathrm{P}=(\mathrm{N})$.

3. $\mathrm{C}_{[\mathrm{ij}]}=\mathrm{A}_{[\mathrm{ij}]}$ for $(0<\mathrm{i}<\mathrm{M}+1)$ y $(0<\mathrm{j}<\mathrm{N}+1)$

4. $\mathrm{C}_{\left[\left(2^{*} \mathrm{M}-\mathrm{i}+1\right), \mathrm{j}\right]}=\mathrm{A}_{[\mathrm{ij}]}$ for $(0<\mathrm{i}<\mathrm{M}+1)$ y $(0<\mathrm{j}<\mathrm{N}+1)$

6. Maintain the value of the $\mathrm{N}$ range of the original matrix.

In the case of sliding symmetry of the horizontal axis (figure 13), points 3 and 4 are changed as follows:

3. $\mathrm{C}_{[\mathrm{ij}]}=\mathrm{A}_{[\mathrm{ij}]}$ for $(0<\mathrm{i}<\mathrm{M}+1)$ y $(0<\mathrm{j}<\mathrm{N}+1)$

4. $\mathrm{C}_{[(2 * \mathrm{M}-\mathrm{i}+1), \mathrm{N}+\mathrm{j}]}=\mathrm{A}_{[\mathrm{ij}]}$ for $(0<\mathrm{i}<\mathrm{M}+1) \mathrm{y}(0<\mathrm{j}<\mathrm{N}+1)$ 


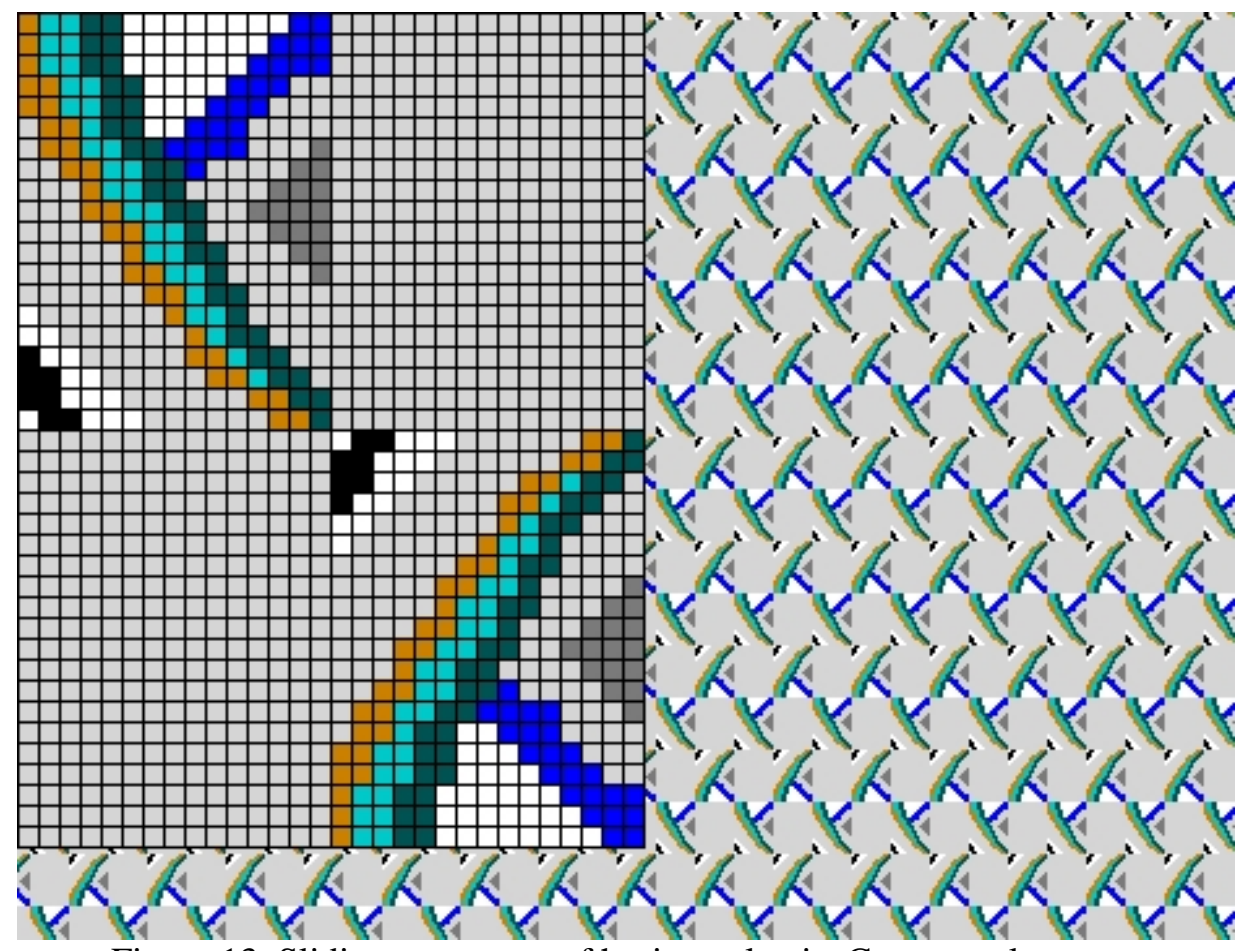

Figure 13. Sliding symmetry of horizontal axis. Current color grey.

In the case of double symmetry (figure 14), the new positioning of the values of the original matrix is resolved with four iterative sequences:

- $\mathrm{C}_{[\mathrm{ij}]}=\mathrm{A}_{[\mathrm{ij}]}$ for $(0<\mathrm{i}<\mathrm{M}+1) \mathrm{y}(0<\mathrm{j}<\mathrm{N}+1)$

- $\mathrm{C}_{[(2 * \mathrm{M}-\mathrm{i}+1),(2 * \mathrm{~N}-\mathrm{j}+1)}=\mathrm{A}_{[\mathrm{ij}]}$ for $(0<\mathrm{i}<\mathrm{M}+1) \mathrm{y}(0<\mathrm{j}<\mathrm{N}+1)$

- $\mathrm{C}_{[(\mathrm{I}),(2 * \mathrm{~N}-\mathrm{j}+1)}=\mathrm{A}_{[\mathrm{ij}]}$ for $(0<\mathrm{i}<\mathrm{M}+1) \mathrm{y}(0<\mathrm{j}<\mathrm{N}+1)$

- $\mathrm{C}_{\left[\left(2^{*} \mathrm{M}-\mathrm{i}+1\right),(\mathrm{j})\right.}=\mathrm{A}_{[\mathrm{ij}]}$ for $(0<\mathrm{i}<\mathrm{M}+1) \mathrm{y}(0<\mathrm{j}<\mathrm{N}+1)$ 


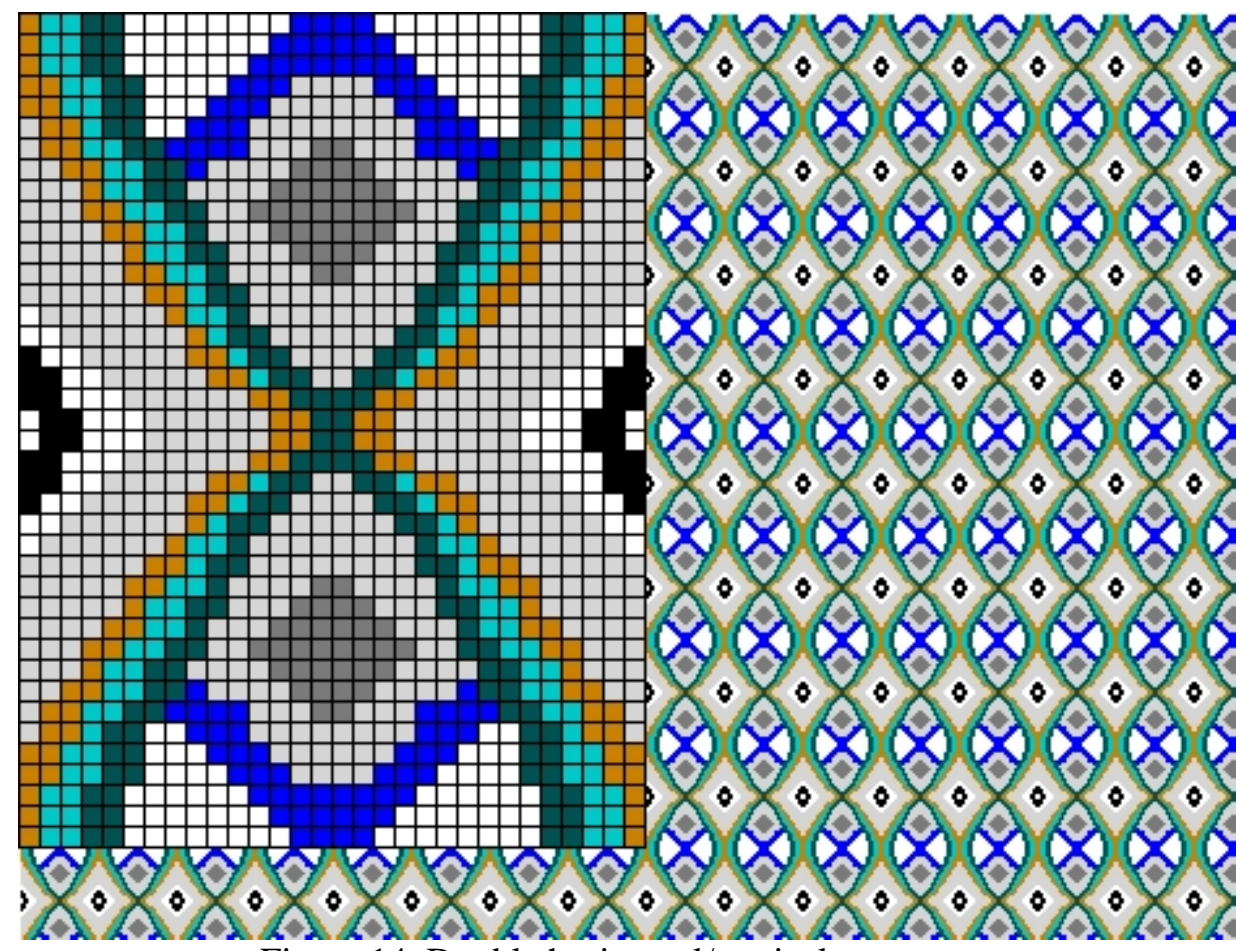

Figure 14. Double horizontal/vertical symmetry

\section{ASSESSMENT OF THE APPLICATION}

The application has been assessed with the help of the group of teachers and their students of the textile specialty in the Higher Technical School of Industrial and Aeronautical Engineering of Terrassa (Barcelona).

The tool was made known to the teachers involved in the process, who in turn offered to assess its effectiveness according to the course they teach. Given that the problems of each course are very specific, each teacher proposed to solve these problems without this tool, and once the problems were solved, the tool was made available to the students, who used it after receiving some brief instructions. The students were then asked to make an assessment of the application, describing its advantages and disadvantages using a report, and also a short questionnaire. The report covered two questions.

The questions were asked during practical laboratory classes in the course "Expresión Gráfica y Diseño Asistido por Ordenador” (Engineering Graphics and Computer-Aided Design), during the week of the $20^{\text {th }}$ to the $24^{\text {th }}$ April 2009, to the 29 students who began the course in February of 2009.

Advice was taken from the Statistics Department of the University. Both the questions and the questionnaire were anonymous, and the aim was explained to the students, along with the fact that 
they were not under any obligation to complete the questionnaire. The students were also informed that the responses should refer to the group of courses, and not to a single course.

1. Explain briefly what are the aspects of the application which have contributed to improving your understanding of specific aspects of the subject matter.

The first question was answered by all the students (29), and the following deductions can be drawn about aspects of the application:

26 students stated that the application had helped them in some way.

21 students replied that the application was very intuitive, and that one if its principal characteristics was to show quickly the results of actions.

12 students replied that the experience was very positive and there should be more programs of this type.

Regarding knowledge about specific aspects of the courses:

25 students stated that the tool had helped them to understand better some of the following textile concepts: textile pattern (18), textile weaving (17), pattern and weft (12), stitching (3), woven fabrics (9)

17 students replied that they had understood better some of the following mathematical concepts: the usefulness of binary numbers (21), applications and correspondences (11), numerical matrices (11), base changes (7), vectors (5), and other concepts (6).

13 students stated that they understood better some of the concepts related to colour.

6 students stated that they understood better the treatment given to lists of data and programming logic.

2. List what you consider are the weak points of the application and explain which aspects you consider should be improved or added to make learning more efficient.

Approximately $60 \%$ of the students (18) replied to the second question, and the following deductions can be made:

16 students highlighted the negative factor of not being able to access the application outside the university. 
9 students indicated that the resolution needed improvement, as it was more limited than professional programs.

7 students suggested ways of making the training more efficient, for example, programming the visualization of other concepts such as the density of the pattern, other colour control systems, movement of pixels to obtain relief, or applying a pattern to predefined objects.

The questionnaire was made up of 5 items, in which the students had to assess the material used on a scale of $1-5$ ( 1 = very unsatisfactory, 2 = unsatisfactory, $3=$ indifferent, $4=$ satisfactory, $5=$ very satisfactory). The detailed results were as follows:

$1^{\text {st }}$ question (overall impression of the experiment)

26 students gave a score of 5

3 gave a score of 4

$2^{\text {nd }}$ question (ease of use of the application)

26 students gave a score of 5

3 gave a score of 4

$3^{\text {rd }}$ question (ease of browsing in the application)

24 students gave a score of 5

5 gave a score of 4

$4^{\text {th }}$ question (Are the actions clear and understandable?)

All the students gave a score of 5

$5^{\text {th }}$ question (Is the response to the action fast?)

All the students gave a score of 5

The approximate averages of the answers to the 5 items of the questionnaire were as follows, and showed a high level of satisfaction.

- $\quad$ Overall assessment $($ mean $=4.9)$

- $\quad$ User friendliness $($ mean $=4.9)$

- $\quad$ Easy browse $($ mean $=4.8)$

- $\quad$ Interaction clear and understandable $($ mean $=5.0)$ 
- $\quad$ Speed of response $($ mean $=5.0)$

\section{USABILITY AND LIMITATIONS}

This IDA is an exceptional tool in the hands of teachers or design professionals or experts, as it incorporates the conceptual basis for a large amount of the knowledge necessary to take full advantage of the imagination of the user. The construction of different knowledge objects has followed a similar process to that used in any research process. Once the object has been detected, a deep analysis of the topic is performed, with a corresponding worldwide search for information, detailed analysis and assessment of its effectiveness and impact.

The solution is then considered using various reasoned proposal, in order to choose the sequence which best combines efficiency with total integration into the environment generated for the application (with the significant reinforcement provided by high quality graphics). This is a new teaching method, with all the advantages of conventional methods and very few of its drawbacks.

Among the current limitations are those relating to the hardware in which the application is run, given that high quality images need processing time, are not scalable, and the means of visualization are not uniform (especially bearing in mind that the application is ideal for use with a classroom projector).

Another limitation relates to the remote use of the application, as it can process large and complex patterns, and therefore the transformation or simulation operations need more time, which along with the network speed, will generate some time outs. However, the application is also being used on a dedicated server, accessible via a local network, and this experience will help to resolve small problems (for example, the blocking system of a file while it is being modified by a remote user, and its freeing once the modification has been concluded) which will not be perceptible when network speeds allow operations to be carried out in memory or if there are downloads of files to local systems. A final limitation is that the software only works on the Windows platform, and currently other operating systems (for example LINUX) are not considered.

\section{CONCLUSIONS: FUTURE WORK}

- The use of this Interactive Didactic Application (IDA) in the teaching of Textile Engineering will reduce the time necessary for the theoretical presentation of some of the key concepts in this 
field, and also in others directly or indirectly related to it. It will improve the speed of the visualization of patterns and simulations, the interpretation of problems and their solutions, and it is also likely to increase the interest and understanding of the students. After the detailed analysis of the qualitative and quantitative data collected, we can deduce that the use of this Interactive Didactic Application in the teaching of Textile Engineering will allow for a reduction in the time necessary to introduce the some of the key concepts in this area, and other related areas. Its use will also improve the speed of visualization of patterns and simulations, the interpretation of problems and their solutions, and so it is also likely that the interest and understanding of students will increase.

During the second experiment, this interest and understanding on the part of the students was shown two final year students and an English student on an Erasmus programme asked to take part in this project using the tool. This would not have been possible without the influence of the director of the project, who took part in the experiment, and whose enthusiasm for the tool led him to recommend it to the students.

- It is evident that this type of material can help to transmit knowledge remotely, as it can be used as a basis for distance learning and be included in possible future virtual libraries.

- The possibility that the students can intervene in the process means that this type of software can evolve with their input. The possibilities for evolution of the application are therefore huge, as in just a short period of use, a large number of suggestions for increasing the actions has been received.

- The assessment carried out shows that the application has a user-friendly interface, is intuitive and has a quick and efficient conceptual response. This shows a high degree of innovation, as there is no application of these characteristics on the market.

- The creation or adaptation of interactive multimedia applications for teaching purposes in an interesting field of work from the point of view of research, as it brings theoretical problems closer to their practical applications. 
- Work in this field contributes to teaching innovation as a vehicle for improvement in teaching quality, and may help multimedia resources play an important role in the analyses proposed by Universities.

- This article presents the IDA specifically in the field of textiles. Previously, other applications with similar methodologies have been used in different branches of science. The analysis of their usefulness and efficiency has given good results, and in the future similar applications may be possible in other knowledge areas.

\section{REFERENCES}

[1] B.R. Barbero, J.P. Vara, E.G. Mate, and J.R. Calvo, Effectiveness of a hypermedia tool in the innovative teaching of pneumatic engineering design drawing, Computer Applications in Engineering Education 15 (2008), 289-307.

[2] L. Ward, and J.M. Parr, Revisiting and reframing use: implications for the integration of ICT, Computers \& Education 54 (2010), 113-122.

[3] J.A. Greene, C.M. Bolick, and J. Robertson, Fostering historical knowledge and thinking skills using hypermedia learning environments: The role of self-regulated learning, Computers \& Education 54 (2010), 230-243.

[4] C. Castejón, D. Blanco, and L. Moreno, Friendly interface to learn stereovision theory, Computer Applications in Engineering Education 17 (2009), 180-186.

[5] C. Evans, and N.J. Gibbons, The interactivity effect in multimedia learning, Computers \& Education 49 (2007), 1147-1160.

[6] T. Kavanagh, J. Matthews, and J. Tyrer, An Inter-Disciplinary Search for Innovation in Textile Design, Proc 86th Textile Institute World Conference, Vol. 2, 2008, 409-422.

[7] N. Starszakowna, Past Tense and Future Perfect Innovation in Textile Design, Proc Magic World of Textiles, 2002, 646-649.

[8] K. Townsend, and C. Jones, Beyond Separation: Managing Innovation in Textile Design, Proc 86th Textile Institute World Conference, Vol. 1, 2008, 516-530. 
[9] K. Y. Jung, Y. J. Na, J. H. Lee, Fdras: Fashion Design Recommender Agent System Using the Extraction of Representative Sensibility and the Two-Way Combined Filtering on Textile. Proc. Database and Expert Systems Applications, 2736 (2003), 631-640.

[10] D. Grundler, and T. Rolich, Evolutionary Algorithms Aided Textile Design, Proc. Magic World of Textiles, 2002, 598-603.

[11] H. Kambe, N. Yamasaki, and M. W. Lee, Super Tex-Sim - Interactive Textile Design and Simulation, Journal of Visualization and Computer Animation, 5 (1994), 265-279.

[12] V. Mandekic-Botteri, The Application of Descriptive Geometry in Textile Design, Tekstil 49 (2000), 237-239.

[13] M. Neves, and J. Neves, Multimedia as a Tool for Distant Learning of Textile Design. Proc. Computational Methods in Engineering and Science, 2003, 687-693.

[14] K. Ohta, H. Nakagawa, and F. Miyawaki, Simulation of Visual Feature of Yarn by Using Fractal Geometry, Sen-I Gakkaishi 55 (1999), 609-612.

[15] P. J. Grigg, A Cad Interface for Textile Design, Computer-Aided Design 15 (1983), 37-40.

[16] A. Taylor, E. Unver, and G. Worth, Innovative Potential of 3d Software Applications in Fashion and Textile Design, Digital Creativity 14 (2003), 211-218.

[17] F. Albert, J. M. Gomis, M. Valor, and J. M. Valiente, Methodology for Graphic Redesign Applied to Textile and Tile Pattern Design, Proc. Innovations in Applied Artificial Intelligence, Vol. 3029, 2004, 876-885.

[18] J. M. Valiente, F. Albert, C. M. Carretero, and J. M. Gomis, Structural Description of Textile and Tile Pattern Designs using Image Processing. Proc. 17th International Conference on Pattern Recognition, Vol 1, 2004, 498-503.

[19] J. M. Valiente, F. Albert, and J. M. Gomis, A Computational Model for Pattern and Tile Designs Classification using Plane Symmetry Groups. Proc. Progress in Pattern Recognition, Image Analysis and Applications, Vol. 3773, 2005, 849-860.

[20] http://www.fractalgraphics.com

[21] http://www.infotex.es 
[22] M. Ochoa-Vives, Incorporación de interfaces gráficas a la simulación de tejidos Jacquard mediante hardware estándar, Ediciones UPC, Barcelona, 1988, p. 409.

[23] http://www.adobe.com/products/authorware/

[24] F. Hernández-Abad, and J. X. Capdevila, Representación por Ordenador de los ligamentos I, Técnica Textil Internacional, 34 (1990), 34-40.

[25] F. Hernández-Abad, and J. X. Capdevila, Representación por Ordenador de los ligamentos II, Técnica Textil Internacional, 35 (1991), 59-62.

[26] F. Hernández-Abad, and J. X. Capdevila, Representación por Ordenador de los ligamentos III, Técnica Textil Internacional, 36 (1992), 37-42.

[27] J. Mumbrú-Laporta, M. Ochoa-Vives, and M. Orellana-Almendras, CAD aplicado al diseño ornamental, Ediciones UPC, Barcelona, 1995, p. 199.

[28] V. Galcerán-Escobet, Tecnología del tejido: Vol. I.: Teoría de Tejidos, Gráficas Costa, Terrassa, 1960. 